A legislação ambiental como foco de conflitos: uma análise a partir das representações sociais da natureza dos pequenos agricultores em Minas Gerais, Brasil Klemens Augustinus Laschefski, Carina Dutra, Sheila Maria Doula

\title{
A LEGISLAÇÃO AMBIENTAL COMO FOCO DE CONFLITOS: UMA ANÁLISE A PARTIR DAS REPRESENTAÇÕES SOCIAIS DA NATUREZA DOS PEQUENOS AGRICULTORES EM MINAS GERAIS, BRASIL
}

\section{Environmental legislation as focus of conflicts: an analysis based on the smallholders' social represen- tations of nature in Minas Gerais, Brasil}

\author{
Klemens Augustinus Laschefski \\ Prof. Adjunto, Universidade Federal de Minas Gerais - UFMG \\ klemens.laschefski@gmail.com
}

Carina Dutra

Geógrafa. Mestre em Extensão Rural pela UFV

carinaadutra@yahoo.com.br

Sheila Maria Doula

Profa. Associada, Universidade Federal de Viçosa - UFV

sheila@ufv.br

Artigo recebido em 24/06/2011 e aceito para publicação em 20/08/2012

RESUMO: A legislação ambiental, freqüentemente, não está sendo respeitada por pequenos produtores rurais. Este trabalho busca entender as razões para este comportamento a partir da análise das representações sociais da natureza e do meio ambiente deste grupo social. Como resultado, constatamos que as representações sociais que formam a base da legislação ambiental não levaram em conta as necessidades básicas para a sobrevivência dos agricultores familiares. Tais necessidades apenas podem ser satisfeitas através do uso de áreas consideradas de alto valor para a preservação do meio natural. Embora os agricultores familiares já tenham incluído a visão oficial da natureza refletida na legislação ambiental no seu imaginário - formando representações sociais híbridas entre visões de mundo modernas e tradicionais - são as materialidades dos seus modos de vida que explicam as aparentes contradições nos seus atos. Desta forma, consideramos a análise das representações sociais uma ferramenta importante na identificação das razões que levam a violações da legislação, que por sua vez podem indicar conflitos ambientais duradouros entre estes grupos e o aparelho repressivo do Estado.

Palavras-chave: agricultura familiar, legislação ambiental, representações sociais, conflitos ambientais

ABSTRACT: Environmental legislation is often not being respected by small farmers. This work seeks to understand the reasons for this behavior through the analysis of social representations of nature and environment of the social group in question. As a result we found out that the social representations which configure the basis of the environmental legislation did not take into account the basic needs for the survival of family farmers. These needs can only be met through the use of areas considered of high value to preserve the natural environment. Allthough the farmers have included in their imagination the official view of nature reflected in the environmental legislation - forming hybrid social representations between modern and traditional world views - it is the materiality of their livelyhoods that explain the apparent contradictions in their actions. Thus, we consider the analysis of social representations an important tool to identify the underlying reasons that lead to violations of the law, which might indicate long-term environmental conflicts between these groups and the repressive state apparatus.

Key words: smallholders, environmental legislation, social representations, environmental conflicts 


\section{INTRODUÇÃO}

O nosso planeta vem sofrendo desde a Revolução Industrial e da formação da sociedade capitalista de consumo com a ação predatória dos recursos naturais. A apropriação da natureza tem se dado desde então de forma indiscriminada, causando problemas ao equilíbrio natural de diversos ecossistemas terrestres. No caso do Brasil, a exploração do bioma da Mata Atlântica, que, aliás, vem ocorrendo desde a chegada dos portugueses ao país, é um exemplo típico da utilização desmedida dos recursos naturais para atender a fins de produção e consumo que tem causado sérios danos à biodiversidade.

Desde os primórdios da colonização, este bioma foi a área de maior concentração de núcleos populacionais e de atividades econômicas, como a exploração de madeiras nobres - como o Pau Brasil, a produção de cana-de-açúcar e café e a pecuária, assim como a mineração, entre outras. $\mathrm{O}$ resultado é que atualmente apenas $6 \%$ da área original são cobertas por este tipo de vegetação, considerada uma das mais ricas no mundo em relação à biodiversidade.

Devido aos problemas resultantes da crescente industrialização, da concentração urbana, do aumento da expectativa de vida, da superpopulação - reflexo das elevadas taxas de natalidade e baixas taxas de mortalidade - bem como da massificação da produção e seus resultados para os ecossistemas terrestres, cresceu a preocupação com os problemas relativos ao que chamamos hoje de meio ambiente. Entendemos aqui que o termo "meio ambiente" circunscreve o conjunto de aspectos relacionais dos seres humanos com o mundo natural, ou seja, a natureza, impactada, influenciada ou modificada pelas atividades humanas. Queremos lembrar, neste contexto, que fenômenos naturais, por sua vez, sempre modificam os objetos artificialmente criados pelos homens (através de erosão, inundações, catástrofes naturais etc.). Os reflexos dessas transformações socioeconômicas apontam para a necessidade da regulação do espaço por parte do Estado, o que vem sendo feito por meio da criação de mecanismos normativos de controle de questões ambientais e de proteção dos recursos naturais.

A legislação ambiental, entretanto, tem também sido foco de conflitos, já que coloca em cena representações sociais diferentes acerca da forma e da utilização dos recursos naturais de um território. É nesse sentido que pretendemos discutir nesse artigo as relações da população rural com o aparato legal construído para dar suporte à proteção do meio ambiente no Brasil. Para tanto, o referencial teórico que irá orientar essa discussão está fundado principalmente na Teoria das Representações Sociais com o intuito de promover o entendimento dos significados e das interpretações atribuídos a fatos, fenômenos, relações cotidianas e, junto a isso, analisar os elementos conflituosos presentes em torno da legislação ambiental geradores de conflitos socioambientais no meio rural.

Neste trabalho procuramos mostrar que as violações da legislação ambiental, recorrentes no campo brasileiro são, pelo menos em parte, resultantes de representações conflitantes entre grupos hegemônicos e grupos que não participaram da elaboração da legislação. Isto porque a própria legislação é baseada em representações da natureza de grupos hegemônicos, representações que são impostas a grupos sociais com práticas distintas de apropriação simbólica e material do espaço natural. Esses indivíduos passam, então, a conviver com um mecanismo de controle legal que tem como foco o disciplinamento do território pelo Estado, que não somente visa a proteção desse espaço, mas também o controle social dos grupos que vivem nesse território (COSTA, 2010). O aparato legal, dessa forma, é a ferramenta com que a representação do Estado se torna a prática e permite a apropriação da realidade, possibilitando assim, segundo Chartier (1990), o processo de apreensão cultural que possibilita ir do discurso ao fato. Nesse sentido, as multas ambientais, como um mecanismo jurídico de controle do regulamento ambiental, podem ser indicativas de uma relação conflituosa entre os agricultores e o sistema ambiental estatal.

\section{REPRESENTAÇÕES SOCIAIS COMO PANO DE FUNDO DE CONFLITOS AMBIENTAIS}

Para Serge Moscovici (2001), as representações sociais são idéias construídas socialmente que servem de base para a interpretação do real. Assim, são construções que sustentam as concepções da realidade entre os grupos, bem como o conjunto das relações 
A legislação ambiental como foco de conflitos: uma análise a partir das representações sociais da natureza dos pequenos agricultores em Minas Gerais, Brasil

Klemens Augustinus Laschefski, Carina Dutra, Sheila Maria Doula

sociais, ou seja, a organização social dos mesmos. Na concepção do autor, trata-se de um corpo conceitual que tem como base as explicações originadas da vivência cotidiana no processo comunicativo. Para Denise Jodelet (2001), as representações sociais são formas de conhecimento social que orientam os comportamentos diante dos diferentes aspectos da realidade. Segundo essa autora, esse conhecimento construído na base diária da vida em comum serve para que seja possível construir uma imagem a respeito do real para que assim os grupos possam se posicionar frente a ele. As representações, segundo a autora, acabam por construir uma visão consensual de mundo, já que são partilhadas pelos grupos na sua vivência diária, mas ao mesmo tempo pode configurar conflitos quando formas distintas de significação de mundo estão em disputa. Portanto, trata-se de categorias que precisam ser analisadas dentro do contexto social no qual estão inseridas, o que demonstra a necessidade de se apreender como os indivíduos constroem suas bases simbólicas e o seu imaginário, fundamentados na sua inserção cultural e socioeconômica, bem como interagem sujeito e sociedade para a construção da realidade. Nesse sentido, importa definir o lugar do qual se fala, assim como os atores sociais envolvidos.

De acordo com Zhouri (2007) "o mundo material é entrecortado por sujeitos sociais que elaboram projetos distintos de uso e significação do espaço, seja ele rural ou urbano" (ZHOURI, 2007, p. 2), o que remete à necessidade de entendimento de que diferentes racionalidades estão presentes em um mesmo espaço. Assim, de acordo com Ascelrad (2005), o meio ambiente deve ser compreendido também como um elemento de contestação e geração de conflitos por se tratar de um espaço comum de recursos no qual estão envoltos sentidos socioculturais e interesses diversificados. O autor assevera, portanto, que em um mesmo espaço estão embutidos ao mesmo tempo valores materiais e simbólicos, que orientam diferentes visões de mundo sobre como deve ser o uso e a ocupação desse espaço. É diante dos diferentes significados atribuídos a uma mesma base material que surgem os conflitos socioambientais. Tais conflitos se inserem em uma esfera de poder na qual estão em tensão diferentes visões de mundo. Sendo assim, os conflitos socioambientais podem ser entendidos como sendo resultado de duas ou mais relações de poder expressas pelas representações sociais em disputa pelo domínio de uma organização socioespacial.

De acordo com Chartier (1990), as representações podem ser pensadas como esquemas intelectuais, que criam as figuras que conferem sentido ao presente e inteligibilidade ao outro e ao espaço ser decifrado. Em outras palavras, as matrizes de discursos e as práticas diferenciadas que orientam os atos, ao permitirem conciliar imagens mentais com esquemas interiorizados de categorias incorporadas, geram e estruturam as representações. Conseqüentemente, na luta entre representações distintas, o que está em jogo não são apenas posições, mas também direitos, hierarquias e, finalmente, a própria ordenação da estrutura social. No contexto deste trabalho entende-se que as diferentes representações sociais em relação a um determinado recorte espacial podem ser a causa de tensões ambientais. Partindo desse pressuposto, consideramos relevantes as idéias de Baczco (1985), para quem é no imaginário social onde se expressam as expectativas e aspirações latentes, constituindo um lugar de conflito entre a ideologia dominante e as forças que se sobrepõem aos dominados. Dessa forma, as representações sociais de um território resultam em conflitos justamente devido a construções imaginárias distintas sobre o uso e ocupação desse espaço.

Para entender os conflitos oriundos desse processo, as representações sociais distintas da natureza e de sua utilização adquirem grande importância, uma vez que indicam o conhecimento pelo qual os grupos constroem o real, refletindo dessa forma, diferentes interpretações. Isto explica porque a utilização dos recursos naturais baseados nas visões das populações rurais, muitas vezes, se choca com a representação social de natureza do Estado, resultando em conflitos territoriais.

Justificamos a importância dessa discussão, já que se tornam cada vez mais necessárias ações em prol de um maior entendimento dos conflitos e tensões em torno da legislação ambiental. Como exemplo, podemos citar a atual discussão em torno do Código Florestal - aparato legal criado em 1934 e reeditado e 1965 com o objetivo de regulamentar o uso das florestas e demais formações vegetais no Brasil - para torná-lo mais flexível em relação aos em- 
preendimentos rurais. Tal reforma torna fundamental o entendimento das diferentes realidades existentes no campo brasileiro para a discussão das modificações por ela propostas. Em outras palavras, um aparato teórico e empírico que revele os elementos do campo pode auxiliar na metodologia utilizada pelos órgãos de desenvolvimento rural. Isso porque, tendo como base a teoria das representações coletivas seria possível lidar com as questões ambientais no campo, a partir das diferentes visões de mundo. Tal debate constitui-se em uma ferramenta importante para tornar útil o conhecimento dos diversos olhares e da interação entre os grupos que se voltam para um mesmo espaço e, ainda, destes com o Estado e seu aparato legal de proteção ao meio ambiente.

O que se percebe é que nas representações que fundamentam as leis sobre a apropriação dos recursos naturais houve um deslocamento do sentido atribuído à natureza, que era anteriormente passível de ser explorada em toda a sua extensão e que passa a ter seu uso limitado. A criação das normas ambientais impôs, portanto, uma reestruturação e uma reorientação dos comportamentos quanto aos recursos naturais no meio rural. De acordo com Pieve, Coelho de Souza e Kubo (2008), percebe-se que a implantação dessas políticas de proteção e fiscalização ambiental no país acaba, muitas vezes, por se confrontar com os modos de vida das populações locais, as quais utilizam os recursos naturais para a alimentação, o comércio, a construção de utensílios domésticos, a ornamentação, os fins medicinais e mesmo místicos. Partimos da hipótese de que esses agricultores entendem a legislação como uma interferência nos seus modos de vida, uma vez que as representações sociais de natureza dos legisladores ainda não foram plenamente assimiladas por aquele grupo. Desta forma, a incompatibilidade da legislação com as suas representações tradicionais é uma das causas que explica a não obediência à lei.

É importante esclarecer que, neste estudo, focalizamos as representações de um grupo de pequenos agricultores familiares. Esse esclarecimento se faz necessário porque entendemos que os conflitos e pressões dos grandes fazendeiros e dos grandes empreendimentos agrícolas capitalistas em relação à legislação ambiental são motivados por outras racionalidades. Cabe alertar que no discurso político dos representantes do grupo de empresários agrícolas há uma tendência a mascarar as grandes diferenças existentes entre esse grupo e os agricultores familiares, cujas representações e práticas ainda são, pelo menos parcialmente, enraizadas em tradições familiares. Assim, as discussões sobre as questões ambientais acabam por inserir todos os grupos em iguais condições no aparato legal, sem considerar as especificidades existentes. Com isso, podemos observar ainda a apropriação dos problemas específicos dos pequenos agricultores de forma generalizada na defesa dos interesses de atores vinculados ao agronegócio globalizado. Por isso, destacamos que os resultados desta pesquisa não podem ser estendidos ao grupo dos grandes empresários agrícolas, cujas representações em relação à legislação ambiental necessitam de um estudo a parte.

\section{O SIGNIFICADO DA NATUREZA NA LEGIS- LAÇÃO AMBIENTAL E NO IMAGINÁRIO DOS AGRICULTORES FAMILIARES}

O foco do estudo centraliza-se nas representações sociais dos agricultores familiares, principalmente no que toca à interferência da legislação ambiental na vida cotidiana, na propriedade e na natureza. Nesse contexto, procuramos ainda compreender quais sentidos têm orientado as práticas dos agricultores familiares em relação ao meio ambiente.

Quando tratamos da propriedade nesse estudo, não nos referimos apenas à propriedade formal de terrenos, imóveis ou bens materiais. Para o agricultor, a propriedade possui uma dimensão simbólica pautada no sustento e na reprodução do grupo familiar. Muitas vezes a propriedade representa a continuidade de um saber que vem sendo ensinado por gerações. Na região estudada, grande parte das propriedades são transmitidas de geração para geração, o que significa um apego maior à terra e um sentimento de pertencimento, já que a propriedade representa um bem da família. E essa pertença pode ainda ser mais forte, tendo em vista que essas propriedades representam o lugar de trabalho e vivência do pai e, em muitos casos, também do avô e até mesmo de gerações anteriores. Portanto, a noção da propriedade é utilizada no sentido de patrimônio.

Sendo assim, considerou-se importante as 
A legislação ambiental como foco de conflitos: uma análise a partir das representações sociais da natureza dos pequenos agricultores em Minas Gerais, Brasil

Klemens Augustinus Laschefski, Carina Dutra, Sheila Maria Doula

contribuições teóricas de Almeida Júnior, Hoeffel e Queda (2008), para os quais a propriedade é tida como um símbolo do imaginário social de um grupo, o que significa que através da aparência da propriedade é possível perceber as representações sociais dos atores no espaço onde vivem. A forma como se dá a organização do local de trabalho, segundo os autores supracitados, é um indicativo do imaginário que irá orientar as práticas desse grupo.

Tendo isso em mente, consideramos que o significado que assume a propriedade para os agricultores influencia nas suas ações no meio ambiente, já que tais formas de entendimento são herdadas do grupo social do qual fazem parte, a partir de saberes transmitidos entre gerações de indivíduos que viveram em um contexto no qual não enfrentavam tantas restrições com relação à utilização dos recursos naturais. Trata-se de uma história de vida e de relações sociais que se institucionalizaram em diferentes épocas no que concerne às relações com a natureza. Dessa forma, para se falar da interação entre os atores sociais e a natureza, é preciso considerar a subjetividade envolvida entre propriedade e sujeito e deste com a natureza, para então entender as representações construídas a respeito da legislação ambiental. Isso significa entender que essa relação resulta de processos internos ao indivíduo e seu grupo social.

Sendo assim, conflitos existentes entre a legislação e as formas de uso e apropriação do espaço natural no meio rural são considerados representativos do significado assumido pela propriedade, bem como do imaginário acerca da natureza, que provém de uma época na qual não havia tantas normas para a proteção ambiental. Tem-se, portanto, uma representação de mundo que está agora em dissonância com a lei.

Tomando como embasamento a teoria das Representações Sociais, pretendemos analisar a conduta dos agricultores familiares com relação à legislação ambiental, partindo do pressuposto de que as ações realizadas pelo grupo resultam de suas visões de mundo, as quais são construídas com base na convivência e interação dentro de um grupo social. Considerando o meio ambiente como encontro de saberes (PORTO GONÇALVES, 2007), certamente que as concepções de natureza irão divergir entre os diferentes grupos sociais. As relações de uma população com o meio natural no qual vive é perpassada por sentidos que são elaborados com base em suas crenças e valores; a própria cultura local é a construtora da paisagem que será, por conseguinte, diferenciada daquela produzida por outro agrupamento social. A teoria das Representações Sociais fornece o embasamento necessário para o entendimento de como as relações sociais no meio rural interagem com o meio ambiente. É o imaginário construído a a partir do significado da natureza e da sua função para esses agricultores que irá orientar as ações do indivíduo nesse mundo.

De acordo com Muggler, Sobrinho e Machado (2006), a relação da sociedade moderna com a natureza se pauta na concepção de natureza provedora, ou seja, disponível para o usufruto da humanidade. Para Silva, Gomes e Santos (2005), a idéia de natureza provedora é forte no imaginário social de alguns grupos, já que representa a possibilidade de sua sobrevivência. Nessa concepção, os recursos naturais representam os meios do agricultor conseguir muitos dos instrumentos que lhes são necessários para a manutenção da propriedade. Em muitos casos, isso se dá para que o indivíduo consiga se manter no circuito da competição capitalista, agredindo portanto o meio ambiente, por ser a forma mais fácil e acessível de conseguir se reproduzir dentro do sistema.

Contudo, um esclarecimento se faz necessário com relação aos grupos pesquisados: temos que diferenciar a concepção de natureza como provedora para fins de sobrevivência, isto é, necessária para o sustento dos grupos; daquela de natureza como provedora de "recursos naturais" a serem aproveitados para a geração de lucro (capital monetário) na sociedade urbano-industrial-capitalista. Isto porque entre as duas concepções de natureza como provedora existem representações distintas e que se refletem na apropriação do espaço físico que têm levado pequenos agricultores a práticas cada vez mais artificializadas. As normas e regras das sociedades não industriais permitem a manutenção da "sustentabilidade" do uso da terra, adaptado aos ritmos naturais que permitem a regeneração permanente dos produtos tirados dos ecossistemas, como por exemplo, através de sistemas de rotação ou de extrativismo migratório. A população geralmente vive em assentamentos pequenos e dispersos e os produtos para suas necessidades são 
acessíveis em distâncias relativamente curtas. As sociedades modernas, contudo, concentram-se em centros urbano-industriais interligados pelas redes de transporte e das tecnologias de informação, enquanto as suas relações com a natureza são cada vez mais alienadas. $\mathrm{O}$ uso da terra apresenta-se como um mosaico de paisagens uniformes, cada um destinado à produção de mercadorias específicas, tais como áreas para a agroindústria, mineração, manejo florestal ou produção de energia (hidrelétricas) etc. Os ritmos e ciclos da natureza são substituídos por insumos técnicos, como adubo e máquinas na agricultura, dentro dos limites da tecnologia disponível. O resultado é a "monoculturação" ambiental e social do espaço, com efeitos não sustentáveis. Tendo em vista a ideologia da acumulação do capital e o crescimento econômico ilimitado, na sociedade moderna, a tendência é a eterna expansão do consumo dos recursos naturais e do espaço.

Estas mudanças da utilização e organização do espaço são resultantes de um processo histórico de modernização da sociedade e foram acompanhadas por profundos conflitos sociais, já que era necessário o rompimento com as regras e a jurisprudência sobre o uso e a propriedade do solo. Essa questão das mudanças na jurisdição nos remete à Marx, que explicou de forma bastante detalhada as transformações dessa ordem ao tratar do processo de acumulação primitiva e ainda em relação ao encercamento das propriedades rurais (enclosure) na Inglaterra no século XVIII (MARX, 1985). Para exemplificar tais mudanças, vale recorrer a Fetzer (2002) que mostrou como os conflitos sobre as terras comuns (Almende em alemão) eram também conflitos sobre a forma da apropriação das florestas. No sistema feudal, as terras comuns eram áreas de uso múltiplo, cuja exploração era baseada num complexo sistema de regras, consolidada na jurisprudência da época. De acordo com as necessidades da população, as áreas comuns foram locais do extrativismo de frutas, castanhas e nozes, lenha, materiais de construção, sistemas silvopastoris entre outros. Contudo, em situações de crise (sobrepopulação, guerras) havia forte degradação desses sistemas, o que levava ao replantio de árvores, atividade que consolidou os fundamentos da engenharia florestal moderna, baseada no conceito do manejo sustentável.
Com a expansão das relações mercantis e do surgimento do capitalismo, os senhores se aproveitaram desta nova técnica florestal para a produção para o mercado (carvão vegetal, material de construção de navios etc.). Contudo, para alcançar esses objetivos era preciso romper com a jurisprudência feudal que garantiu o usufruto das áreas comuns dos camponeses. O processo se estendeu por quase três séculos e é considerado uma das causas das guerras dos camponeses no século XVII (FETZER, 2002).

A idéia da preservação natural surgiu no contexto da apropriação técnica do espaço em decorrência do avanço do capitalismo. Diante das conseqüências negativas sobre a natureza, surgiu na época do romantismo, no século XIX, a idéia que algumas áreas teriam que ser protegidas de interferências humanas, ou seja, a apropriação capitalista desses espaços teria que ser limitada. Hoje esta representação se reflete em estratégias de grandes ONGs, como o World Wide Fund for Nature (WWF), que propõem a proteção de áreas de alto valor em termos de conservação. Conforme Diegues (1996), esta representação está baseada em uma concepção de "natureza intocada". Entretanto, o autor nos chama a atenção para o fato de que sobretudo populações tradicionais estão praticando formas da etnoconservação, mesmo que nunca tenham tido a necessidade de expressar verbalmente a necessidade de cuidar do meio ambiente ou preservar a natureza. Neste contexto, os principais modos de apropriação da natureza estão também voltados para a manutenção do funcionamento dos processos de regeneração natural para garantir a sobrevivência de gerações futuras.

De forma paradoxal, é justamente a legislação ambiental moderna que, frequentemente, impossibilita a continuação desses modos de vida, como por exemplo, o nosso Código Florestal, que proíbe a agricultura nas margens de rios, embora justamente estas áreas sejam aquelas que, deste o surgimento do homem, possibilitaram a sobrevivência das comunidades, já que as enchentes fertilizavam o solo utilizado, garantindo a sustentabilidade ecológica da produção. $\mathrm{O}$ deslocamento de tais pessoas força a utilizarem fertilizantes artificiais em outros lugares, gerando novos problemas ambientais.

Entendemos que as multas ambientais podem ser vistas como a materialização do conflito entre as 
A legislação ambiental como foco de conflitos: uma análise a partir das representações sociais da natureza dos pequenos agricultores em Minas Gerais, Brasil

Klemens Augustinus Laschefski, Carina Dutra, Sheila Maria Doula

representações embutidas na legislação ambiental e aquelas dos agentes sociais no meio rural. A representação social do Estado sobre o meio ambiente está amparada pela lei e claramente expressa no caput do artigo 225 da Constituição Federal. Dessa forma, de acordo com a lei ambiental, todos os indivíduos

\section{“(...) têm direito ao meio ambiente ecologi- camente equilibrado, bem de uso comum do povo e essencial à sadia qualidade de vida, impondo-se ao Poder Público e à coletivida- de o dever de defendê-lo e preservá-lo para as presentes e futuras gerações" (BRASIL, Constituição Federal, 1988, p. 204 ).}

Pelo parágrafo da Constituição, o meio ambiente é um direito fundamental desta geração e das gerações futuras e a responsabilidade de fazer com que isso seja possível é de competência de toda a sociedade que, para tanto, é fiscalizada e tem seus atos sobre a natureza controlados. Nesse sentido, ao poder público fica a incumbência de garantir a sustentabilidade dos recursos naturais e esse poder é garantido por meio da legislação ambiental. Diferentemente dessa concepção, encontra-se a posição de muitos atores sociais no meio rural, que têm na natureza fontes de recursos essenciais para a manutenção e sobrevivência da propriedade e, ainda, para a reprodução do grupo familiar. Ocorre então o choque de duas representações sociais distintas sobre o uso e ocupação de um mesmo espaço. Nessa ausência de diálogo entre o poder público e a população, desconsidera-se o fato de que os agricultores partilham um modo de vida que se constrói muitas vezes a base de muito sofrimento, devido às dificuldades que enfrentam nas atividades rurais diariamente, bem como, em muitos casos, da insuficiência de renda para adquirir determinados produtos por meio da compra.

De acordo com Pieve, Coelho de Souza e Kubo (2008), tem-se a evidência de que existe de um lado uma legislação não dialógica, punitiva e restritiva com relação ao uso dos recursos naturais e, de outro, há uma população que depende desses recursos para sobreviver e que não chega a degradar a ponto de causar uma destruição significativa do meio ambiente. Dessa forma, é preciso considerar a grande diversi- dade local e cultural dos grupos sociais, não podendo assim as diferenças culturais serem tratadas da mesma forma pela lei ou mesmo serem igualadas às demais categorias de produção que, em muitos casos, são sim altamente poluentes.

\section{REPRESENTAÇÕES SOCIAIS E CONFLITOS AMBIENTAIS NA REGIÃO CAMPO DAS VER- TENTES - MG}

A análise tomou como base as narrativas e as práticas cotidianas de um grupo de agricultores de um município situado na região do Campo das Vertentes, no estado de Minas Gerais. A base principal da economia na área estudada é a agropecuária. A pecuária abrange grande parte das ocupações locais, ocupando espaço mais importante do que a agricultura na composição da renda. Com relação à produção agrícola no município, sobressai o cultivo de banana, café, laranja, feijão, milho e arroz. (IBGE, 2007) Quanto às características físicas da região, prevalece um relevo bastante acidentado, característico dos mares de morros de Minas Gerais; a vegetação nativa é a Mata Atlântica que está, em alguns pontos, bastante conservada. No que concerne aos recursos hídricos existentes, o local é cortado pelos ribeirões Piranga e Papagaio, que pertencem à bacia do rio Doce.

Para que pudéssemos entender como as diferentes representações sociais materializam entre os agricultores, adotamos como procedimentos metodológicos a associação livre, método através do qual o entrevistado é estimulado a dizer o que lhe vem à cabeça quando estimulado por uma palavra ou situação. O carro chefe para dessa metodologia foi a palavra natureza. Optamos nesta situação por este vocábulo, pois a pesquisa focalizou principalmente a relação dos entrevistados com as áreas protegidas pela legislação para a finalidade de preservar a natureza. Além disso, também lançamos mão de entrevistas semi-estruturadas que contaram com um roteiro contendo quinze questões. O total de entrevistados somou dezessete pessoas, todos vinculadas à agricultura familiar, sendo que treze deles lidavam com a pecuária e os demais com a agricultura. Essa amostra está de acordo com o delineamento qualitativo dessa pesquisa que não requer grande número de entrevistados para 
a análise. Não tínhamos como pretensão construir generalizações, visto que estamos trabalhando com um estudo de caso. Além disso, alcançamos com esse número de entrevistas um momento de saturação das informações, quando não observávamos variações significativas nas falas. O critério para compor a amostra era ser agricultor familiar morador do município. Os agricultores foram selecionados com base em um banco de dados por nós construído durante os primeiros levantamentos e que tomou como referência a numeração das residências. Posteriormente prosseguimos com o sorteio daquelas por meio dos números das casas que teriam um de seus membros convidado a colaborar com a pesquisa. O tempo médio de duração de cada entrevista foi de cerca de trinta minutos, sendo realizadas quatro entrevistas por dia, em média. Para fazer referência a passagens ilustrativas das entrevistas, e ainda, manter o anonimato os entrevistados, serão identificados por letras selecionadas aleatoriamente. As entrevistas foram transcritas sem que houvesse qualquer alteração, mesmo em relação à correção gramatical.

Através do método da associação livre, solicitamos que os entrevistados mencionassem as palavras que lhes viessem à mente quando estimulados a partir do vocábulo natureza. A ancoragem, que segundo Jodelet (2001) é o enraizamento da representação, que permite a explicação dos fatos de uma maneira familiar e a classificação dos elementos e das situações, foi percebida nesse caso principalmente em torno do elemento árvore, compartilhada por todos os entrevistados. Sugere-se que este elemento aparece freqüentemente nas falas por se tratar do recurso citado, nas entrevistas semi-estruturadas, como o mais utilizado pelo grupo. Outras evocações comuns ao campo das representações sociais entre esses agricultores perpassam elementos como animais e rios.

As associações mais freqüentes demonstram uma representação de natureza que está, no discurso, distante do ser humano, visto que as referências a ela pertencem ao domínio do natural, do físico e não relacionado ao ser humano; o homem não está presente diretamente nas falas de nenhum dos entrevistados como sendo parte da natureza. No entanto, ao analisar-se a menção aos elementos árvore e rios, pode-se perceber no imaginário desse grupo a idéia de natureza provedora, fonte de recursos para a sobrevivência, estando dessa forma implícita a referência ao homem como relacionado ao meio natural, já que ele depende diretamente dos recursos naturais. Desta forma, embora não verbalmente expresso, há um certo tipo de convivência direta com elementos naturais como necessária para a manutenção do modo de vida das famílias. Esta concepção se choca com a visão imposta pelos órgãos públicos, que é, conforme já mencionado, principalmente baseada na valorização de uma "natureza intocada", ou seja, de um preservacionismo que prevê o impedimento ou, pelo menos, fortes restrições da atividade humana nas respectivas áreas.

Conseqüentemente, as entrevistas semi-estruturadas apontaram através dos discursos dos agricultores que a legislação ambiental tem influenciado as representações sociais de natureza entre eles, tendo em vista que muitos, assustados com a possibilidade de recebimento de multas ambientais e com receio também das penas de reclusão, passam a ver a natureza como algo proibido. Os recursos naturais surgem então, no imaginário social dos entrevistados, como dotados de regras, regulamentados e protegidos por um alto poder, representado pela lei, que tem a competência de punir aqueles que usam os recursos naturais quando existem restrições legais para tanto. Assim, frases como "(...) povo tem muito medo (...)" e “(...) agora não pode mais cortar (lenha) (...)" são freqüentemente mencionadas nas respostas e são elucidativas da presença de novos sentidos e significados que moldam a representação social de natureza entre esses agricultores. Sendo assim, entende-se, nos termos defendidos por Jodelet (2001), que as representações sociais são uma mediação entre o sujeito e o mundo em que vive. Dessa forma, os indivíduos lançam mão do seu sistema de significados, do seu conhecimento prévio de mundo, para interpretarem novas situações, torná-las familiares e criarem referências a respeito dela. A apropriação do novo, nesse caso, passa pela idéia da natureza como algo restrito e/ou proibido. Assim, a representação da natureza insere-se, agora, no aparato de regras impostas, que levam a sua classificação para o campo das interdições e do perigo.

No entanto, apesar de as representações de natureza estarem ancoradas no campo do proibido, sete agricultores mencionaram ter a necessidade de 
A legislação ambiental como foco de conflitos: uma análise a partir das representações sociais da natureza dos pequenos agricultores em Minas Gerais, Brasil

Klemens Augustinus Laschefski, Carina Dutra, Sheila Maria Doula

retirar madeira da mata em alguns casos. A resposta fornecida por " $A$ " é ilustrativa nesse sentido "(...) a gente precisou de um pedaço de pau grande pra fazer a ligação da luz (suporte para os fios e para o transformador de energia), aí a gente tirou lá no meio, lá em cima (...)".

Assim, freqüentemente, a implementação da legislação ambiental é causa de conflitos, pois a falta de acesso aos recursos naturais significa uma perda material, que precisa ser compensada por outros meios, como por exemplo, através do mercado. $\mathrm{O}$ quadro se agrava, entretanto, quando os indivíduos não possuem fontes de renda que permitam a compra desses bens. Neste contexto, a exploração de áreas protegidas continua a acontecer em função das necessidades reais de subsistência desses grupos, atividades que muitas vezes já vêm sendo praticadas por gerações, mas que se tornam atos ilegais frente à legislação ambiental recente.

A colocação acima demonstra a existência de uma dissonância entre os imaginários sociais, ou nos termos defendido por Acselrad (2005), um conflito de racionalidades, quanto à importância da proteção do meio ambiente. De um lado temos as representações que movem as ações do Estado e que são por ele ditadas por meio da lei, do outro nos deparamos com entendimento do assunto por parte dos agricultores. Estes, embora tenham seu imaginário influenciado pelo poder punitivo da legislação, ainda fazem uso de alguns recursos existentes em sua propriedade movidos pela necessidade, principalmente da madeira. A passagem anterior pode ainda ser ilustrada com a resposta de "B", ao confirmar o uso dos recursos naturais "(...) quando a gente precisa a gente tira, fazê o que? Pra compra fica caro (...)". A retirada a qual esse agricultor se refere é voltada para a construção de cercas, galinheiros, chiqueiros, currais e para a utilização da madeira nos fogões à lenha. Tais colocações demonstram que, embora haja uma nova representação social de natureza sendo construída pelo Estado, o imaginário do grupo sobre os recursos naturais não está sendo alterado substancialmente. Pudemos verificar que os agricultores entrevistados lançam mão de práticas que foram construídas ao longo do tempo e que não são abandonadas por eles por fazerem parte das suas tradições. Nesse sentido, percebemos ainda, que os recursos naturais nesses casos são necessários do ponto de vista prático da reprodução familiar.

Outro elemento significativo apreendido das entrevistas semi-estruturadas que demonstra a influência da legislação nas representações sociais locais sobre a natureza surgiu por meio do discurso de alguns agricultores sobre as práticas ambientais dos vizinhos. As contradições encontradas no discurso do grupo foram bastante ricas no sentido de facilitar a compreensão de quais as representações estão em primeiro plano para esses agricultores, já que existem custos sociais e econômicos envolvidos pelas necessidades básicas desse grupo social. Freqüentemente um agricultor denunciava a utilização de recursos restritos por lei pelos outros agricultores. Enquanto alguns dos entrevistados defendem não agredirem o meio ambiente, outros mencionavam, por exemplo, que alguns deles retiravam a madeira no meio da mata para evitar que a ação fosse vista por quem passasse pela estrada, de forma que os órgãos fiscalizadores não pudessem ter conhecimento do corte ilegal. O fragmento da fala de um agricultor é esclarecedor nesse sentido ao informar que "(...) aos pouquinho, o "C" vai limpano tudo lá em cima $(. .$.$) ". Esse agricultor se refere ao corte de$ madeira para a venda realizada por outro agricultor, que vem retirando a mata no centro da propriedade de forma a camuflar a ação e que a mesma não possa ser percebida.

Também a caça de animais silvestres foi mencionada por esses agricultores como sendo uma ação que muitos ainda praticavam no lugar, como a captura de pássaros como os periquitos-verdes -Brotogeris Tirica.- e que, segundo uma agricultora, quase não existem mais na região devido à caça. Essa mesma agricultora fez referência ainda à caça da espécie que ela nomeou como trinca-ferro - Saltator Similis -, um pássaro muito valioso por seu canto, bem como por seu temperamento agressivo e por isso muito usado em rinhas. Importa mencionar, entretanto, diante do fato que muitos atores sociais não respeitam a lei, que é preciso considerar a realidade social desses agricultores e ainda entender a maneira como a vida social foi sendo construída. É necessário considerar principalmente os motivos que fundamentam a construção dessas representações sociais (CHARTIER, 1990) para que possamos entender o porquê de tais 
sujeitos não agirem de acordo com a lei ambiental.

Ao ser feita referência à propriedade, treze dos entrevistados responderam terem vivido no lugar durante toda a vida e tê-la herdado do pai. Além disso, para essa parcela de entrevistados, todo o conhecimento sobre uso da "sua terra" foi construído no trabalho diário ao lado do genitor. A propriedade enquanto elemento simbólico é o espaço de trabalho, lugar de vivência e ainda local de trabalho dos antepassados que viviam em um contexto bastante diferente em termos da utilização dos recursos naturais. Importa considerar que as regras e normas quanto à utilização desses recursos foram se instituindo em diferentes épocas. Assim, convém mencionar que as diferenças institucionais sobre a proteção do meio ambiente orientam representações diferentes com relação à natureza. Como bem menciona Jodelet (2001), as representações sociais são uma forma de conhecimento socialmente elaborado e compartilhado que contribuem para a construção de uma realidade comum a um conjunto social. Entretanto, apesar de se ter toda uma tradição construída por um grupo juntamente com a elaboração de práticas que se deram ao longo de muitos anos, os agricultores entrevistados que hoje colocam em prática o conhecimento recebido dos seus genitores estão em desacordo com a legislação ambiental.

O que se percebe é que as normas modernas que regulamentam o uso do meio natural contribuem para uma alteração no imaginário social com relação ao meio ambiente, anteriormente visto como fonte para satisfazer as necessidades diárias desses agricultores. A utilização dos recursos existentes na propriedade é também a base para a reprodução do grupo social, já que muitas vezes o valor despendido com a compra do recurso, sendo a madeira o mais citado nas respostas, pode comprometer a subsistência da família. Assim, a representação de natureza expressa na legislação ambiental passa, do ponto de vista desses agricultores, em primeiro lugar, pela idéia do proibido, do restrito pela lei. Ao mesmo tempo, os sujeitos criam formas de adaptação a esta situação, procurando caminhos para que os seus atos que contrariam as normas não sejam descobertos. Assim, a grande maioria continua a retirar os recursos necessários da propriedade, driblando a lei, porém obedecendo a elementos de primeira ordem como atender às necessidades básicas do grupo.
Com relação ao conhecimento dos agricultores sobre a legislação ambiental, apesar de não saberem definir do que se trata, ficou claro que os entrevistados têm em seu imaginário a consciência de determinados aspectos como, por exemplo, que o aparato legal é gerador de multas. Contudo, no encontro entre o imaginário social desse grupo e aquele imposto pela lei, percebe-se que há entre os agricultores uma avaliação diferenciada de determinadas atividades. Sendo assim, enquanto a retirada de mata seca para o uso no fogão à lenha e para a construção de cercas para a propriedade era considerada aceitável entre eles do ponto de vista legal, eles também possuíam o conhecimento de que o corte de mata verde não era permitido por lei. Isto se reflete na informação obtida de uma entrevistada sobre três vizinhos que estariam retirando lentamente a vegetação da propriedade para a venda de lenha na cidade, ou ainda, para produzir carvão. As necessidades básicas do grupo apontam novamente para os elementos que são centrais nas representações desses sujeitos. É o que se percebe com o caso citado acima, já que se tem uma legislação que restringe o uso, mas ao mesmo tempo, há as necessidades básicas de um grupo que precisam ser atendidas e, para tanto, são acionados os elementos práticos constituídos pela tradição.

Com relação às multas, todos os entrevistados negam ter recebido qualquer valor a pagar por ações ilegais quanto aos recursos naturais da propriedade. Entretanto, de acordo com informações fornecidas pelos agricultores a respeito dos demais, quatro daqueles que negaram ter recebido multas foram punidos com o pagamento de valores, principalmente pelo corte ilegal de madeira, havendo inclusive reincidência.

Desta forma, há, à primeira vista, uma contradição no discurso entre a enfatizada defesa do meio ambiente e as práticas reais desses agricultores com relação aos recursos naturais, pois existe a retirada de madeira ilegal da propriedade, por exemplo. Essa situação evidencia um choque de representações entre o que prevê o Estado e o que necessitam e pensam os agricultores entrevistados. Por um lado, existe uma representação social de natureza no campo do proibido, por outro lado, ainda permanece no imaginário a natureza que provê as necessidades humanas. É importante, contudo, destacar que os sujeitos entre- 
A legislação ambiental como foco de conflitos: uma análise a partir das representações sociais da natureza dos pequenos agricultores em Minas Gerais, Brasil

Klemens Augustinus Laschefski, Carina Dutra, Sheila Maria Doula

vistados falam de um determinado lugar e possuem determinadas posições sociais frente aos moradores locais, mas também frente ao Estado, o que nos remete a considerar as diferentes realidades sociais nas quais esses indivíduos estão envolvidos. Tais condições se refletem no discurso, já que, como menciona Foucault (2008), em toda sociedade o discurso é selecionado. Assim, nem tudo pode ser dito a qualquer momento, uma vez que o discurso como fonte de poder precisa ser contido. A discrepância entre discurso e prática explica-se, assim, através das representações distintas que esses sujeitos têm diante dos moradores locais, bem como das condições enfrentadas por essas pessoas no dia-a-dia e do mundo "lá fora", representado pelos agentes do Estado que aplicam as multas.

De fato, embora os entrevistados sejam unânimes em defender a legislação ambiental como necessária para a proteção do meio ambiente, apesar de não entenderem exatamente o porquê da importância, dez dos agricultores pesquisados não acreditam que algo grave possa vir a acontecer no meio rural devido às degradações no local. Isso porque para esses agricultores o espaço rural já é bastante preservado, enquanto os fenômenos de degradação ambiental são primordialmente associados somente ao meio urbano. Esse ponto do discurso aponta para a representação social de um rural ligado à idéia de natureza, local de ar puro, no qual os recursos estão protegidos. Tais representações, como lembra Jodelet (2001), agrupam elementos afetivos, mentais e sociais que integram na linguagem o imaginário que se constrói da realidade material.

Os agricultores mencionaram ouvir freqüentemente falar de problemas ambientais na televisão, mas não conferem importância à temática, já que os termos utilizados são pouco claros. Atribui-se a isso, o fato de que o discurso ambiental midiático, principalmente na televisão, meio de comunicação mais citado por eles, é proferido em escalas muito amplas de entendimento, as quais não contribuem para a compreensão da situação por estar muito distante da realidade diária dessas pessoas. Dessa mesma forma, as informações recebidas que não condizem com o campo simbólico das representações desse grupo não são capazes de produzir real significado. Por isso, a compreensão que o grupo entrevistado possui do meio ambiente obtidas dos meios de comunicação é bastante distante da realidade por eles vivida, já que os discursos pela mídia transmitidos não trazem elementos do universo simbólico dessas pessoas frente à uma abordagem em ampla escala que não contribui para o entendimento da questão ambiental a nível local.

Apesar de todos informarem acreditar na importância da legislação para proteção do meio ambiente para a vida humana, somente quatro dos entrevistados souberam dizer quais atitudes são adotadas dentro da propriedade para a proteção ambiental. Entre as atitudes consideradas nocivas ao meio ambiente, os entrevistados tiveram plena consciência de condições prejudiciais mencionando, por exemplo, que o esgoto é despejado nos rios e ainda que o lixo, em cerca de $70 \%$ das residências pesquisadas, é eliminado nos rios devido à ausência de infraestrutura no lugar. O restante dos informantes afirmou levar o lixo até a cidade para ser recolhido pela prefeitura, resposta que pode ter sido condicionada pelo medo diante das restrições ambientais impostas. Tivemos essa impressão uma vez que tais afirmativas foram contestadas pelos demais entrevistados.

As entrevistas permitiram ainda verificar que alguns agricultores usam técnicas de proteção ao meio ambiente, mas não por influência da legislação ambiental. Essas práticas, podem ainda estar ligadas às tradições desses agricultores. Um deles mencionou usar as cabeças de bois mortos na propriedade para construir ninhos para pássaros, de forma a evitar que eles fossem roubados ainda enquanto filhotes. Essa prática já era realizada pelo pai desse agricultor e que também poderia estar relacionada a questões de superstição como "espantar o mal olhado", por exemplo. Os pássaros acabavam tomando esse objeto para a construção de seus ninhos. Esse mesmo entrevistado mencionou fazer denúncias contra a caça de pássaros silvestres em sua propriedade. Outros agricultores afirmaram realizar o plantio de árvores e proteger as nascentes, mesmo que esta última ação seja somente para que não se esgote a água que abastece a propriedade. Algumas dessas ações não demonstram exatamente razões relacionadas à proteção do meio ambiente, mas sim questões práticas que correspondem às necessidades da vida diária, enquanto outras são realizadas por motivos que são também alheios 
à questão ambiental como a estética da propriedade, como mencionado por um agricultor para justificar o plantio de árvores.

\section{CONSIDERAÇÕES FINAIS}

Por meio dessa pesquisa foi possível verificar a existência de conflitos socioambientais entre duas representações sociais de mundo; de um lado, tem-se a posição defendida pelo Estado e que está respaldada por um aparato legal - a legislação ambiental - e de outro, tem-se o imaginário dos agricultores, que se volta para as necessidades básicas da propriedade como representativa do bem da família, aquilo que é responsável pela reprodução do grupo familiar.

Assim, pelo que se pôde verificar, o grupo de agricultores familiares pesquisado adota práticas ambientais que não condizem com aquelas normatizadas pela legislação. As práticas estão muito relacionadas com o aprendizado que obtiveram durante a vida acerca da natureza e da propriedade da família com o grupo social no qual estão inseridos. Isso porque apesar do excesso de normatização a que estão submetidos esses agricultores, eles continuam a valorizar a sua tradição e permanecem desenvolvendo as atividades que aprenderam ao longo da vida com os genitores. Assim, embora a legislação ambiental possa trazer determinadas alterações nas práticas desses agricultores, ela apenas altera superficialmente as representações sociais desse grupo em relação ao meio ambiente. $\mathrm{O}$ que foi possível perceber é que o grupo construiu uma relação com a natureza que está muito ligada à questão das necessidades básicas da família, por isso, muitas vezes surge a necessidade de burlar a lei ambiental.

É nesse sentido que foi fundamental interpretar as representações sociais do sujeito dentro do contexto histórico do qual o discurso é proferido, considerando, dessa forma, quem fala e de onde fala. O sujeito lança mão de elementos simbólicos e de aspectos culturais para tornar compreensível para si e para os outros a realidade vivida. Portanto, analisar as representações sociais dos indivíduos por meio do discurso exige que o olhar esteja voltado para os processos interacionais, relacionais e culturais entre os grupos, que tem os seus significados atribuídos pelo contexto.
Os agricultores aqui estudados podem ser considerados como representantes de culturas híbridas, que mesclam tradição e modernidade. Por um lado eles praticam usos da terra de acordo como aprenderam das gerações anteriores, por outro lado já foram contatados por agentes do Estado, que promoveram a modernização dos modos de produção agrícola, voltado ao mercado e para a nova legislação ambiental, que protege áreas ainda não transformadas. Porém, são justamente aquelas florestas que foram utilizados para a produção de lenha, cercas, madeira de construção, entre outros, que estão hoje na mira dos preservacionistas da hegemonia. Assim, explicam-se formas contraditórias de representações, sobretudo, quando consideramos os supostos usos predatórios. Alguns desses usos realmente transformam áreas protegidas dentro de uma lógica capitalista em outros usos da terra e, assim, realmente violam a lei. Já outros, na margem da sobrevivência, continuam com o uso das florestas em pé como aprenderam dos seus pais, justificado com a necessidade, mas não com o objetivo da transformação total.

Os resultados das entrevistas trazem à tona a necessidade de se considerar a subjetividade dos grupos sociais para entender o fluxo de suas representações sociais. Estudos dessa natureza abrem espaço para se pensar nas limitações e nas dificuldades que esses grupos enfrentam na vida diária e da necessidade que os atores sociais possuem de usar os recursos que a propriedade dispõe. Importa não perder de vista que esses agricultores não chegam a causar um prejuízo ambiental que possa ser considerado significativo. Assim, torna-se preponderante para as políticas ambientais no meio rural não igualar o agricultor familiar aos grandes empreendimentos agrícolas, como se faz em muitos aspectos da legislação.

\section{REFERÊNCIAS}

ASCELRAD, H. Apresentação. In: A Insustentável Leveza da Política Ambiental. Desenvolvimento e Conflitos Socio-Ambientais. Belo Horizonte: Autêntica, 2005.

ALMEIDA JR; HÖEFFEL, J. L. de M. \& QUEDA, O. A propriedade rural como símbolo. São Paulo: Hucitec, 2008. 
A legislação ambiental como foco de conflitos: uma análise a partir das representações sociais da natureza dos pequenos agricultores em Minas Gerais, Brasil

Klemens Augustinus Laschefski, Carina Dutra, Sheila Maria Doula

BRASIL. Constituição da República Federativa do Brasil, DF: Senado, 1988.

CHARTIER, R. A. História Cultural: entre práticas e representações. Tradução Maria Manuela Galhardo. Rio de Janeiro: Bertrand Brasil, 1990. 245p.

DA COSTA, G. V. L. A entrada do direito na resolução de um conflito ambiental: A gestão personalizada de uma Unidade de Conservação na Praia do Aventureiro (Ilha Grande, RJ). Dilemas. Estudos de conflito e controle social, v. 7, p. 9-31, 2010.

DIEGUES, A. C. O mito da natureza intocada. São. Paulo: Hucitec, 1996.

FETZER, R. Der Kampf um den Wald. Zeitschrift für die Geschichte des Oberrheins, v. 150, p. 161-183. 2002.

FOUCALT, M. A ordem do discurso. Aula inaugural no College de France, pronunciada em 2 de Dezembro de 1970. Tradução de Laura F. de A. Sampaio. Edições Loyola, São Paulo, 2008.

JODELET, D. As representações sociais: um domínio em expansão. In: JODELET, D. (org.) As representações sociais. Rio de Janeiro: EdUERJ. 2001.

MARX, Karl. A Chamada Acumulação Primitiva. In: O Capital. Lv. I, Vol. 2, São Paulo: Difel, 1985.

MOSCOVICI, S. Das representações sociais às representações coletivas. In: JODELET, D. (org.) As representações sociais. Rio de Janeiro: EdUERJ. 2001.

MUGGLER, C. C.; PINTO SOBRINHO, F. de A.; MACHADO, V. A. Educação em solos: princípios, teoria e métodos. Rev. Bras. Ciênc. Solo, Viçosa, v. 30, n. 4, Aug. 2006 Disponível em: http://www. scielo.br/scielo.php? script $=$ sci_arttext\&pid $=\mathrm{S} 0100$ $-06832006000400014 \& \operatorname{lng}=\mathrm{en} \& \mathrm{nrm}=\mathrm{iso}$, Acesso em 11 Nov. 2010.

PIEVE, S. M. N.; COELHO DE SOUZA, G.; KUBO, R. R. Conflitos sócio-ambientais: o papel da legisla- ção ambiental na utilização de recursos naturais. In: $3^{\circ}$ Encontro da Rede de Estudos Rurais - Tecendo o intercâmbio: diversidade e perspectivas do mundo rural no Brasil contemporâneo, 2008, Anais... Campina Grande, 2008.

PORTO-GONÇALVES, C. W. A globalização da natureza e a natureza da globalização. Civilização Brasileira: Rio de Janeiro, 2006.

SOUSA JUNIOR, W. C. de. Gestão das Águas no Brasil: Reflexões, Diagnósticos e Desafios/IEB . São Paulo: Peirópolis, 2004.

ZHOURI, Andréa. Conflitos Sociais e Meio Ambiente Urbano. Série Documenta EICOS, Comunidades, Meio Ambiente, Desenvolvimento, $\mathrm{n}^{\circ} 17,2007$. Disponível em: http://www.psicologia.ufrj.br/pos_eicos/ pos_eicos/arqanexos/documenta/documenta17_artigo4.pdf 